\title{
On-Demand Therapy Is a Valid Strategy in GERD Patients: Pros and Cons
}

\author{
Andreas Leodolter ${ }^{a}$ Roberto Penagini ${ }^{b}$ \\ ${ }^{a}$ Medical Department, Ev.-Jung-Stilling Hospital, Academic Hospital of the University of Bonn, Siegen, Germany; \\ ${ }^{b}$ Cattedra di Gastroenterologia, Dipartimento di Scienze Mediche, University of Milan, and Fondazione IRCCS \\ Ospedale Maggiore, Mangiagalli, Regina Elena, Milan, Italy
}

\section{Key Words}

On-demand GERD treatment - Gastroesophageal reflux disease $\cdot$ On-demand GERD therapy, pros and cons · Proton pump inhibitors

\begin{abstract}
On-demand proton pump inhibitor (PPI) therapy is an attractive option for long-term management of gastroesophageal reflux disease (GERD). Controlled trials in non-erosive reflux disease (NERD) patients have shown sufficient symptom control in most patients with a high rate of willingness to continue treatment and substantial saving on PPI expenditure. However, due to the slow onset of action of PPIs, rescue antacids are often used when symptoms recur and several patients continue to experience some degree of heartburn. On-demand treatment is less cost-saving in patients with esophagitis, and symptomatic/endoscopic relapses occur frequently in severe grades. Data on the prevention of long-term sequelae of on-demand treatment are scarce, only indirect evidence being available. It is suggested that PPI continuous maintenance is more appropriate than on-demand therapy in patients with severe esophagitis, in those with Barrett's esophagus where chronic PPIs may reduce incidence of dysplasia, in uninvestigated elderly patients where esophagitis is more prevalent and it is more fre-
\end{abstract}

quently complicated with gastrointestinal bleeding and possibly in uninvestigated or NERD patients with frequent clinical relapses. Finally, more appropriate outcome variables should be used in future trials in order to assess efficacy of on-demand treatment adequately.

Copyright $\odot 2007$ S. Karger AG, Basel

\section{Pros by Andreas Leodolter}

According to the recent global definition, gastroesophageal reflux disease (GERD) is defined as a condition which develops when the reflux of stomach contents cause troublesome symptoms and/or complications [1]. From the patient's perspective, sufficient symptom control is the most important goal of therapy. At least $60 \%$ of patients in primary care with troublesome reflux symptoms have no endoscopically recognizable lesions of the esophageal mucosa, 35\% have erosive esophagitis (75\% Los Angeles grade A/B, 25\% Los Angeles grade C/D). In about $5 \%$ of the patients, serious complications, such as stricture, ulcer and in particular Barrett's esophagus or even adenocarcinoma, must be expected [2]. Overall, around $90 \%$ of patients with GERD have no or only mild lesions in their esophagus. Given the fact that progression from mild to severe disease is a very rare event, preven-

\section{KARGER}

Fax +4161306 1234

E-Mail karger@karger.ch

www.karger.com
(C) 2007 S. Karger AG, Basel

$0257-2753 / 07 / 0253-0175 \$ 23.50 / 0$

Accessible online at:

www.karger.com/ddi
Prof. R. Penagini

Fondazione IRCCS Ospedale Maggiore Policlinico

Mangiagalli e Regina Elena, Pad Granelli

Via F. Sforza 35, IT-20122 Milano (Italy)

Tel. +39 025503 3311, Fax +39025503 3644, E-Mail roberto.penagini@unimi.it 
tion of esophageal complications in all patients with GERD seems to be an inappropriate goal of treatment. Furthermore, it is unclear whether symptom-controlled proton pump inhibitor (PPI) maintenance therapy reliably prevents progression to more severe stages of the disease.

On-demand therapy is an attractive option for the long-term management of the majority of GERD patients. Patients are instructed to take one dose of a PPI, if required, for the relief of heartburn, and stop treatment when their heartburn is adequately controlled. The effectiveness of this approach has been shown in many randomized controlled studies in patients with non-erosive reflux disease (NERD) and uninvestigated GERD without any alarm features prompting endoscopy, respectively [3-9]. Sufficient control of GERD symptoms is possible in the vast majority of patients responding to an initial 'healing phase' with a PPI given daily over 4 weeks. In one study, on-demand treatment with a PPI was even superior to maintenance therapy with another PPI [10]. The mean daily intake of a PPI is reduced by around two thirds compared to daily intake of a PPI implying substantial cost saving [3-8]. Patients with erosive GERD should be divided in those with mild esophagitis (Los Angeles grade A/B) and those with severe disease (Los Angeles grade C/D). The latter group is not sufficiently treatable with an on-demand therapy because relapse of esophagitis is a frequent finding despite sufficient symptom control [11]. But in mild erosive disease on-demand treatment seems to be an appropriate strategy, since it offers similarly effective symptom control compared to continuous therapy [11]. A higher relapse rate of mild erosive esophagitis seems to be less important because immediate complications are not to be expected and progression in the long run is probably negligible.

Empirical PPI therapy is commonly prescribed in patients with uninvestigated GERD. This strategy seems to be safe since the vast majority of patients suffering from GERD symptoms have benign disease. Endoscopy is neither a sensitive nor a specific method for the diagnosis of GERD. Moreover, endoscopic classification systems of esophagitis and Barrett's esophagus are prone to interobserver variability questioning all strategies based on endoscopic findings. A once-in-a-life-time upper gastrointestinal endscopy in GERD patients favored by some authors, but it is probably unrealistic. After an initial therapy with continuous PPI treatment, patients can be switched to an on-demand therapy. In a large trial [9] around $75 \%$ were satisfied with on-demand therapy, slightly less than in the continuously treated patient group (82\%). This might due to the unknown number of patients with severe esophagitis. In addition, the direct and indirect costs of the on-demand therapy were significantly lower [12], a factor which is getting more and more important in times of limited resources of healthcare systems.

Future studies will have to clarify whether patients could be identified without the need of endoscopy on the basis of demographic characteristics, individual risk factors and the response to PPI therapy. Such algorithms have been proposed very recently [13]. They should be validated in large population-based studies. The fact that a symptom-driven strategy incorporating the on-demand concept has not been extensively studied could not be used as an argument for competing strategies since neither an endoscopy-based approach to the long-term management of patients with GERD nor the 'preventive' effect of continuous intake of a PPI has been formerly validated.

One of the major concerns might be about the power of on-demand therapy for prevention of long-term sequelae of GERD. There is not much evidence about it, but over a 20 -year period, the severity of reflux esophagitis does not increase in most patients [1]. In the recent ProGERD trial, most patients remain in the NERD and Los Angeles grade A/B category in a prospective 2-year follow-up with treatment at the discretion of their physician. But mild esophagitis behaves in a similar way to NERD with considerable movement between the categories. The progression to a severe esophagitis or Barrett's esophagus was a rare event $(<1 \%)$ and not significantly influenced by the intake of PPI, other factors are more likely to be of importance [14]. In a long-term course of GERD, patients up to 20 years and a symptom-driven therapy only in $11 \%$, a worsening of mucosal lesions was observed. The incidence of strictures was $0.1 \%$ in the NERD group and $1.8 \%$ in the ERD groups revealing that symptom-driven therapy can avoid the complications of GERD [15]. Therefore, we have indirect evidence that progression, even under on-demand therapy, is an infrequent finding.

Therapy of GERD should be concentrated on symptoms in patients with NERD and mild ERD, and on-demand PPI therapy is able to control symptoms sufficiently in most patients. Acceptance of an on-demand therapy by the patients is high and there is no evidence that this strategy will increase the risk of complications of GERD. 


\section{Cons by Roberto Penagini}

On-demand therapy has recently been proposed as a cost-effective strategy for long-term management of patients with GERD $[3,5,7,8]$. However, the available data are far from conclusive.

\section{Symptom Control}

Acid-suppressive treatment is quite frequent; $1-6 \%$ of the population takes acid-suppressive medications and $45-60 \%$ of indications are GERD-related $[16,17]$. It is now well known that $30-80 \%$ of the patients take them intermittently or on demand in spite of prescriptions for continuous treatment $[17,18]$. This occurs for a variety of reasons: first of all depending on presence and/or severity of symptoms, but also for fear of side effects or addiction and for lack of knowledge regarding the reasons why the treatment was needed and how it worked [19]. It is interesting to note that, according to a general practitioner database in the Netherlands [17], adherence to PPI maintenance treatment is independent of presence of esophagitis, $40 \%$ of the patients taking non-continuous treatment. Only when the indication for treatment was Barrett's esophagus, continuous treatment was followed by around $80 \%$ of the patients. Although one could suppose that patients in the community are satisfied with their 'self-modified' often non-continuous treatment, this is not the case. Only $36 \%$ of them are asymptomatic, $21 \%$ take at least one form of over-the-counter medication and even when the main therapy is a PPI, only $60 \%$ of the patients consider their treatment 'very effective' [20]. These epidemiological data seem to be in contrast with the positive results of placebo-controlled trials of on-demand therapy in NERD patients $[3,5,7,8]$. As described in the Pro section above, these trials, which allowed patients to take only one PPI tablet/day, have shown a high willingness of patients to continue on-demand PPI and substantial savings on PPI expenditure compared to continuous treatment. However, on one side, willingness to continue was very high in the placebo arms as well (48-68\% of patients), on the other the number of antacid tablets was not negligible in the PPI on-demand arms (0.31-0.91/day), suggesting that results need to be considered with caution. Firstly these trials have used willingness to continue, number of days that PPIs were used and frequency of need for rescue antacids as outcome variables, which are not the most appropriate ones in order to assess effectiveness of an acid inhibitory treatment. Severity of individual symptoms and especially of heartburn, and number of symptom-free days should be ana- lyzed in future trials as it has been usually done when evaluating continuous treatment. Secondly, a consistent antacid use is explained by the pharmacodynamic properties of PPIs; maximal inhibition of acid secretion occurs after a few days of intake [21], which induces patients to take antacids in the meantime and makes on-demand treatment an unsuitable modality for this class of drugs. As a matter of fact, when, during an open study, more than 1 PPI tablet/day was allowed, the mean daily number of PPI tablets approached 1 , which is similar to the amount used during continuous treatment [22]. Finally, we do not know if on-demand therapy prevents longterm sequelae of GERD as no long-term (beyond 2 years) studies are available, although this should not be a major concern in patients with NERD [23].

Several data in the literature suggest that continuous maintenance PPI therapy should be preferred to on-demand PPI in patients with esophagitis, in the elderly and in patients with Barrett's esophagus.

\section{Patients with Esophagitis}

Continuous treatment with PPIs is effective in maintenance of healing in patients with esophagitis [24]. Ondemand PPIs should be discouraged especially in patients with more severe grades of esophagitis (i.e. Los Angeles grades $\mathrm{C}$ and $\mathrm{D}$ ) because endoscopic and symptomatic relapses occur in $35-50 \%$ of them [11]. Furthermore, sparing of PPI tablets is less marked than in patients with NERD (0.57-0.73 tablets/day) [11, 25].

\section{Uninvestigated Elderly Patients}

It has been shown that prevalence of esophagitis above age 60 is much higher than in younger patients in spite of a similar or milder clinical picture [26]. Furthermore, esophagitis becomes a major cause of bleeding in elderly patients with a prevalence of $21 \%$ above age 80 [27]. These data suggest that continuous PPIs should be a safer modality of maintenance treatment.

\section{Patients with Barrett's Esophagus}

Ex vivo studies have shown that pulses of acid induce proliferation in Barrett's, but not in the squamous epithelium of the esophagus [28]. Proliferation is markedly decreased when intraesophageal acid exposure is normalized by PPIs [29], and recent uncontrolled studies have suggested that long-term PPI treatment reduces incidence of dysplasia [30, 31]. Although not conclusive, these observations suggest that continuous inhibition of acid secretion should theoretically be preferred in symptomatic patients with Barrett's esophagus. 


\section{References}

1 Vakil N, van Zanten SV, Kahrilas P, Dent J, Jones R: The Montreal definition and classification of gastroesophageal reflux disease: a global evidence-based consensus. Am J Gastroenterol 2006;101:1900-1920.

$\checkmark 2$ Quigley EM: Non-erosive reflux disease: part of the spectrum of gastro-oesophageal reflux disease, a component of functional dyspepsia, or both? Eur J Gastroenterol Hepatol 2001;13(suppl 1):S13-S18.

-3 Bytzer P, Blum A, De Herdt D, Dubois D: Sixmonth trial of on-demand rabeprazole $10 \mathrm{mg}$ maintains symptom relief in patients with non-erosive reflux disease. Aliment Pharmacol Ther 2004;20:181-188.

4 Kaspari S, Kupcinskas L, Heinze H, Berghofer P: Pantoprazole $20 \mathrm{mg}$ on demand is effective in the long-term management of patients with mild gastro-oesophageal reflux disease. Eur J Gastroenterol Hepatol 2005; 17:935-941.

5 Lind T, Havelund T, Lundell L, Glise H, Lauritsen K, Pedersen SA, Anker-Hansen O, Stubberod A, Eriksson G, Carlsson R, Junghard O: On-demand therapy with omeprazole for the long-term management of patients with heartburn without oesophagitis - a placebo-controlled randomized trial. Aliment Pharmacol Ther 1999;13:907-914.

-6 Scholten T, Dekkers CP, Schutze K, Korner T, Bohuschke M, Gatz G: On-demand therapy with pantoprazole $20 \mathrm{mg}$ as effective longterm management of reflux disease in patients with mild GERD: the ORION trial. Digestion 2005;72:76-85.

7 Talley NJ, Lauritsen K, Tunturi-Hihnala H, Lind T, Moum B, Bang C, Schulz T, Omland TM, Delle M, Junghard O: Esomeprazole 20 $\mathrm{mg}$ maintains symptom control in endoscopy-negative gastro-oesophageal reflux disease: a controlled trial of 'on-demand' therapy for 6 months. Aliment Pharmacol Ther 2001;15:347-354.

-8 Talley NJ, Venables TL, Green JR, Armstrong D, O'Kane KP, Giaffer M, Bardhan KD, Carlsson RG, Chen S, Hasselgren GS: Esomeprazole $40 \mathrm{mg}$ and $20 \mathrm{mg}$ is efficacious in the long-term management of patients with endoscopy-negative gastro-oesophageal reflux disease: a placebo-controlled trial of on-demand therapy for 6 months. Eur J Gastroenterol Hepatol 2002;14:857-863.

$\checkmark 9$ Norman Hansen A, Bergheim R, Fagertun $\mathrm{H}$, Lund $\mathrm{H}$, Moum B: A randomised prospective study comparing the effectiveness of esomeprazole treatment strategies in clinical practice for 6 months in the management of patients with symptoms of gastroesophageal reflux disease. Int J Clin Pract 2005;59: 665-671.
10 Tsai HH, Chapman R, Shepherd A, McKeith D, Anderson M, Vearer D, Duggan S, Rosen JP: Esomeprazole $20 \mathrm{mg}$ on-demand is more acceptable to patients than continuous lansoprazole $15 \mathrm{mg}$ in the long-term maintenance of endoscopy-negative gastro-oesophageal reflux patients: the COMMAND Study. Aliment Pharmacol Ther 2004;20:657-665.

11 Sjostedt S, Befrits R, Sylvan A, Harthon C, Jorgensen L, Carling L, Modin S, Stubberod A, Toth E, Lind T: Daily treatment with esomeprazole is superior to that taken ondemand for maintenance of healed erosive oesophagitis. Aliment Pharmacol Ther 2005; 22:183-191.

12 Norman Hansen A, Wahlqvist P, Jorgensen E, Bergheim R, Fagertun H, Lund H, Moum B: Six-month management of patients following treatment for gastroesophageal reflux disease symptoms - a Norwegian randomized, prospective study comparing the costs and effectiveness of esomeprazole and ranitidine treatment strategies in a general medical practitioners setting. Int J Clin Pract 2005;59:655-664.

13 Bytzer P, Blum AL: Personal view: rationale and proposed algorithms for symptombased proton pump inhibitor therapy for gastro-oesophageal reflux disease. Aliment Pharmacol Ther 2004;20:389-398.

14 Labenz J, Nocon M, Lind T, Leodolter A, Jaspersen D, Meyer-Sabellek W, Stolte M, Vieth M, Willich SN, Malfertheiner P: Prospective follow-up data from the ProGERD study suggest that GERD is not a categorial disease. Am J Gastroenterol 2006;101:24572462.

15 Sontag SJ, Sonnenberg A, Schnell TG, Leya J, Metz A: The long-term natural history of gastroesophageal reflux disease. J Clin Gastroenterol 2006;40:398-404.

16 Jacobson BC, Ferris TG, Shea TL, Mahlis EM, Lee TH, Wang TC: Who is using chronic acid suppression therapy and why? Am J Gastroenterol 2003;98:51-58.

17 Van Soest EM, Siersema PD, Dieleman JP, Sturkenboom MC, Kuipers EJ: Persistence and adherence to proton pump inhibitors in daily clinical practice. Aliment Pharmacol Ther 2006;24:377-385.

18 Hungin AP, Rubin GP, O’Flanagan H: Longterm prescribing of proton pump inhibitors in general practice. Br J Gen Pract 1999;49: 451-453.

19 Hungin AP, Rubin G, O’Flanagan H: Factors influencing compliance in long-term proton pump inhibitor therapy in general practice. Br J Gen Pract 1999;49:463-464.

20 Jones R, Armstrong D, Malfertheiner P, Ducrotte P: Does the treatment of gastroesophageal reflux disease meet patients' needs? A survey-based study. Curr Med Res Opin 2006;22:657-662.
21 Cederberg C, Thomson AB, Mahachai V, Westin JA, Kirdeikis P, Fisher D, Zuk L, Marriage $B$ : Effect of intravenous and oral omeprazole on 24-hour intragastric acidity in duodenal ulcer patients. Gastroenterology 1992;103:913-918.

22 Juul-Hansen P, Rydning A: On-demand PPI requirements in patients with endoscopynegative GERD. J Clin Gastroenterol 2004; 38:746-749.

23 Bayerdorrfer E, Sipponen P, Bigard M, Weiss W, Mearin F, Rodrigo L: Esomeprazole 20 $\mathrm{mg}$ continuous versus on-demand treatment of patients with endoscopy-negative reflux disease. Gut 2004;53:A106.

24 Vakil NB, Shaker R, Johnson DA, Kovacs T, Baerg RD, Hwang C, D’Amico D, Hamelin B: The new proton pump inhibitor esomeprazole is effective as a maintenance therapy in GERD patients with healed erosive oesophagitis: a 6-month, randomized, double-blind, placebo-controlled study of efficacy and safety. Aliment Pharmacol Ther 2001;15: 927-935.

25 Johnsson F, Moum B, Vilien M, Grove O, Simren M, Thoring M: On-demand treatment in patients with oesophagitis and reflux symptoms: comparison of lansoprazole and omeprazole. Scand J Gastroenterol 2002; 37:642-647.

26 Collen MJ, Abdulian JD, Chen YK: Gastroesophageal reflux disease in the elderly: more severe disease that requires aggressive therapy. Am J Gastroenterol 1995;90:10531057.

27 Zimmerman J, Shohat V, Tsvang E, Arnon R, Safadi R, Wengrower D: Esophagitis is a major cause of upper gastrointestinal hemorrhage in the elderly. Scand J Gastroenterol 1997;32:906-909.

28 Fitzgerald RC, Omary MB, Triadafilopoulos G: Dynamic effects of acid on Barrett's esophagus. An ex vivo proliferation and differentiation model. J Clin Invest 1996;98: $2120-2128$.

29 Ouatu-Lascar R, Fitzgerald RC, Triadafilopoulos G: Differentiation and proliferation in Barrett's esophagus and the effects of acid suppression. Gastroenterology 1999;117: 327-335.

30 El Serag HB, Aguirre TV, Davis S, Kuebeler M, Bhattacharyya A, Sampliner RE: Proton pump inhibitors are associated with reduced incidence of dysplasia in Barrett's esophagus. Am J Gastroenterol 2004;99:18771883.

31 Hillman LC, Chiragakis L, Shadbolt B, Kaye GL, Clarke AC: Proton-pump inhibitor therapy and the development of dysplasia in patients with Barrett's oesophagus. Med J Aust 2004;180:387-391. 